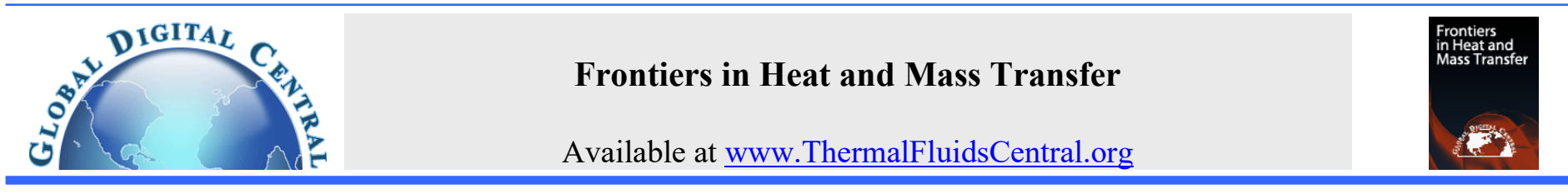

\title{
EFFECTS OF EVAPORATING TEMPERATURE ON FLOW PATTERN IN A HORIZONTAL EVAPORATOR
}

\author{
Andriyanto Setyawan ${ }^{\mathrm{a}}$ \\ ${ }^{a}$ Department of Refrigeration and Air Conditioning Engineering, Politeknik Negeri Bandung, Bandung 40012, Indonesia
}

\begin{abstract}
In this paper, the effect of evaporating temperature on the void fraction and flow pattern of R290 in an evaporator of air conditioning unit has been studied. The analysis was carried out for evaporator diameter of $7.9 \mathrm{~mm}$ and $6.3 \mathrm{~mm}$ and cooling capacity of $2.64 \mathrm{~kW}$ and $5.28 \mathrm{~kW}$. The analysis was conducted at evaporating temperature of $-20^{\circ} \mathrm{C}$ to $+5^{\circ} \mathrm{C}$ with an increment of $5^{\circ} \mathrm{C}$. At the inlet of evaporator, the void fraction ranges from 0.932 to 0.984 , whereas at the outlet the void fraction is 1 . Testing the void fraction by using 3 available correlations gives the good agreement, with an average error of less than $5 \%$. For all ranges of evaporating temperature, the analysis of flow pattern using larger pipe and smaller cooling capacity results in the domination of wavy flow and slug flow. Using smaller pipe and smaller cooling capacity provides transition from wavy and slug flow to annular flow, and results in the domination of annular flow up to $75 \%$. Doubling the cooling capacity with smaller evaporator pipe increases the portion of annular flow up to $84 \%$. In general, lower evaporating temperature will give the higher void fraction and higher annular flow portion.

Keywords: Flow pattern, void fraction, evaporator, R290, cooling capacity.
\end{abstract}

\section{INTRODUCTION}

In refrigeration and air conditioning applications, especially in evaporator and condenser, two-phase flow can be easily found. Void fraction and flow pattern are two important aspects in two-phase flow. The void fraction expresses the ratio of pipe area filled by gas or vapor to the total cross-sectional area of the pipe. Meanwhile, the flow pattern deals with how liquid and gas or vapor of fluid travel in a channel. Two key parameters in flow pattern are velocity and spatial distribution of liquid dan gas or vapor.

Studies and research concerning to void fraction have been carried out and many methods have been employed. Using refrigerants R134a and R410A, an experimental study to determine the void fraction of channel with diameter of $7.3 \mathrm{~mm}$ and $8.9 \mathrm{~mm}$ (Yashar et al., 2001). It was reported that the void fraction of micro fin tube is similar to that of smooth tube. Void fraction prediction of the same refrigerants by utilizing probabilistic flow map has been proposed (Jassim and Newell, 2006). It could predict the void fraction of all refrigerants for a wide range of flow quality. Correlation for predicting void fraction for refrigerant R410A, R134a, R22, R12, and R11 has been proposed utilizing 1574 data points (Xu and Fang, 2014). The proposed correlation was developed by involving fluid density, flow quality, Froude number, and homogeneous void fraction. Kanizawa and Ribatski (2015) proposed void fraction correlation for R410A, R134a, R22, and R12 employing the density, viscosity, Froude number, and Weber number. The most comprehensive study was accomplished which involving large data points, including 1110 data from $\mathrm{CFC}$, HCFC, HFC, and natural refrigerants (Bhagwat, and Ghajar, 2014). Meanwhile, simplified correlation involving only Reynolds number of vapor and liquid has been proposed by Setyawan et al. (2019a). The void fraction in the last correlation was expressed in term of liquid holdup. Later, the void fraction correlation from Kanizawa and Ribatski (2015) has been tested by R717 and R744 data and provided a good agreement (Pietrzak and Płaczek, 2019).

Different flow patterns could be found in evaporator: bubble, slug, plug, wavy, and annular. Bubble slug is characterized by the presence of gas bubble in the liquid flow. In slug flow, liquid with small bubbles travels and pushes a larger size bubble. Plug flow is characterized by a continuous liquid with large and long bubbles suspended in the liquid. In stratified flow or stratified smooth flow, liquid is separated from gas and travels in the bottom while gas travels in the top of pipe. If the gas velocity increases, the turbulence in the interface of gas and liquid will also increase. This cause a wavy interface and the flow pattern is called as stratified wavy flow or simply wavy flow. In annular flow, the vapor refrigerant flow in the pipe center, surrounded by the liquid refrigerant that flows in the pipe wall. The thickness of the liquid refrigerant depends on the circumferential position in the pipe (Setyawan et al., 2016,2017).

Methods for determining the flow pattern of refrigerant have been developed for decades. ECT (electrical capacitance tomography) has been used to determine the structure of multiphase flow in real-time situation, as reported by Warsito and Fan (2001). Capacitance signal has also been employed for determining the flow pattern (Caniere et al., 2008) and this method has been used by Caniere et al. (2010) for mapping the flow pattern of refrigerant R134a and R-410A in an 8-mm pipe. Intermittent flow, slug flow, and annular flow were encountered in this experiment.

The use of neural network for identification of flow pattern has been applied for refrigerant R-134a in horizontal pipe (Roman et al., 2015). For high pressure system, a flow pattern map for R170 in 4-mm horizontal pipe with saturation pressure of 1.5 to $2.5 \mathrm{MPa}$ has been developed by Zhuang et al. (2016). Slug, plug, wavy-annular, and smooth annular were investigated in the experiment. The improvement of flow pattern map in horizontal micro fin pipe has been developed. In 
some variation of microfin helix angle, it was reported that the flow patterns were similar to those of smooth tube (Yang and Hrnjak, 2020).

The studies and experiments for identifying the flow pattern during boiling of refrigerant have been extensively carried out. Intermittent, stratified, stratified-wavy, and annular flow were identified by Zürcher et al. (2002) in experiment with ammonia refrigerant in 14-mm horizontal tube. Meanwhile, slug, plug, bubble, and annular flow were studied in an experiment using R32 in rectangular microchannel with size less than $1 \mathrm{~mm}$. Bubbly flow was encountered only when the flow quality of refrigerant is very low, or when the superficial velocity of vapor is very low (Tu and Hrnjak, 2004). The similar flow patterns were identified in an experiment using 3 different refrigerants and channels with diameter of 1-3 mm (Ong and Thome, 2009). The behaviors of flow and the mechanism of heat transfer in micro channel have also been investigated by Saisorn and Wongwises (2012).

Visualization experiment of flow pattern of R134a in horizontal, vertical, and inclined tube with diameter of $8.9 \mathrm{~mm}$ has been carried out, in which annular, wavy-annular, and stratified-wavy flow were observed for experiment in horizontal orientation (Mohseni and AkhavanBehabadi, 2014). In this research, the flow pattern map was developed based on the Weber number of vapor and liquid phase. Using isobutane as refrigerant, a visualization experiment for identifying the flow pattern in an 8.1-mm diameter of horizontal tube has been carried out by Shafaee et al. (2016). Bubbly and stratified flow were encountered in this experiment, but intermittent and annular flow were the dominant patterns. The use of coiled wire inserted in the pipe provided an acceleration of transition from intermittent flow to annular flow. It was also reported that the coiled wire improved the heat transfer coefficient by $24 \%$. Later, a visualization of flow of refrigerant R32 in microchannel has been performed by Li and Hrnjak (2019). The experiment was conducted in parallel microchannel of $0.643 \mathrm{~mm}$ diameter. Plug/slug, transition, and annular flow was observed in this experiment.

This paper deals with the influence of evaporating temperature on flow pattern of refrigerant R-290 when it travels in a horizontal evaporator. The methods for determining the void fraction and flow pattern will be discussed. Elaboration on the behavior of void fraction over the range of experimental condition will be presented. The analysis of how evaporating temperature affects the flow pattern will also be described.

\section{RESEARCH METHOD}

\subsection{Air conditioning system}

In an air conditioning system that employs refrigeration cycle with vapor compression, refrigerant is subjected to four processes as shown in Fig. 1. Process 1-2 is compression, in which refrigerant in vapor state is compressed by the compressor. The high-pressure vapor is the condensed in a condenser (2-3) and a pure liquid phase is resulted at the outlet of the condenser. In process 3-4, refrigerant flows through an expansion device. At the outlet, the pressure of refrigerant decreases and the phase changes into a mixture of liquid and vapor. In evaporator (4-1), refrigerant evaporates and absorb heat from the surrounding. The evaporation process in evaporator causes the fraction of liquid decreases and the fraction of vapor increases. At the evaporator outlet, the refrigerant is completely evaporated to avoid liquid slugging in the compressor. The liquid/vapor fraction depends on the condition of refrigerant at the inlet of expansion device and the evaporating pressure and temperature.

\subsection{Void fraction}

Based on the definition, the void fraction could be determined by

$$
\alpha=\frac{V_{G}}{V_{L}+V_{G}}
$$

where $\alpha$ denotes the void fraction, $V$ is the pipe volume, and subscripts $L$ and $G$ represent the phase of refrigerant, liquid or vapor. To calculate the pipe volume occupied by vapor and liquid, the following equations apply

$$
\begin{gathered}
V_{G}=x * v_{G} \\
V_{L}=(1-x) * v_{L}
\end{gathered}
$$

In the las two equations, $x$ denotes the vapor quality, representing the ratio of vapor mass to total mass of refrigerant and $v$ denotes the specific volume of refrigerant. Both parameters could be found in the pressure-enthalpy diagram of refrigerant.

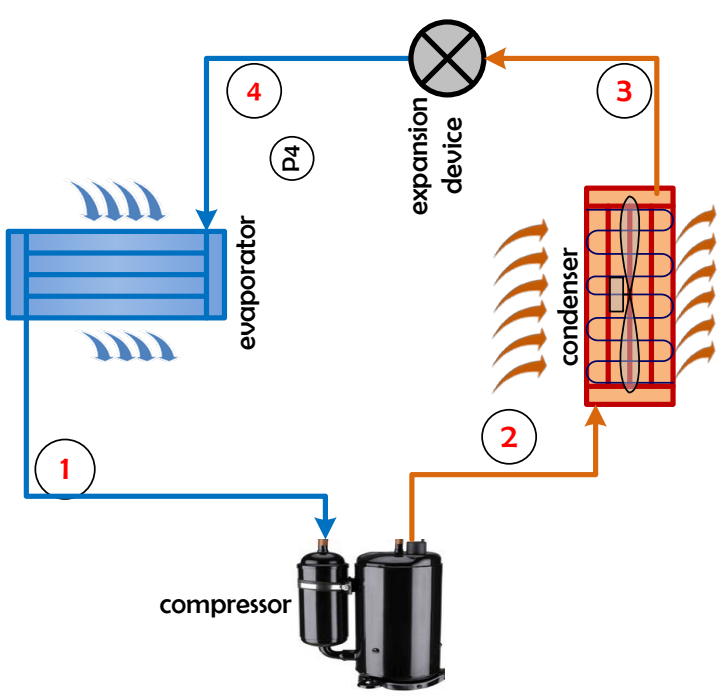

a.

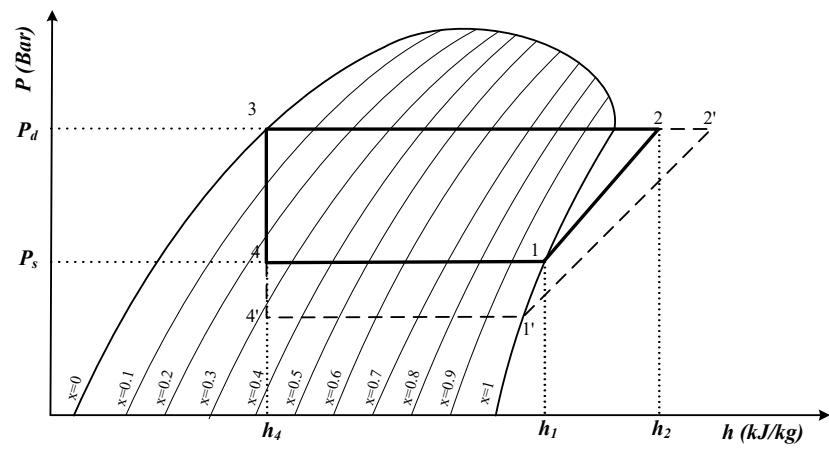

Fig. 1 Air conditioning system (a). components, and (b). pressure vs enthalpy diagram

\subsection{Flow pattern}

To determine the flow pattern in evaporator, the superficial velocity of refrigerant for both phases should be determined first. The vapor superficial velocity, $J_{G}$, could be calculated using the following relation

$$
J_{G}=\frac{\text { volumetric flow rate of vapor phase }}{\text { area of pipe }}=\frac{Q}{A}
$$




$$
J_{G}=\frac{Q \rho_{G}}{A \rho_{G}}=\frac{\dot{m}_{G}}{\left(\frac{\pi D^{2}}{4}\right) \rho_{G}}
$$

The similar expression is used for liquid superficial velocity, $J_{L}$,

$$
J_{L}=\frac{Q \rho_{L}}{A \rho_{L}}=\frac{\dot{m}_{L}}{\left(\frac{\pi D^{2}}{4}\right) \rho_{L}}
$$

where $\dot{m}_{G}$ and $\dot{m}_{L}$ are refrigerant mass flow rate in vapor and liquid phase, respectively, $\rho$ is refrigerant density, and $D$ is pipe inner diameter. To calculate $\dot{m}_{G}$ and $\dot{m}_{L}$, the total mass flow rate $(\dot{m})$ should be calculated first.

$$
\begin{gathered}
\dot{m}=\frac{Q_{E}}{\Delta h_{E}} \\
\dot{m}_{G}=\dot{m} x \\
\dot{m}_{L}=\dot{m}(1-x)
\end{gathered}
$$

Once the $J_{G}$ and $J_{L}$ are obtained, the flow pattern could be determined by plotting both phase velocities in the two-phase flow map. In this case, the $J_{G}$ and $J_{L}$ will be plotted in Mandhane Map (Mandhane et al., 1974; Setyawan et al., 2019b).

In this paper, the horizontal evaporator with a length of $\mathrm{L}$ is divided into 20 segments. Analysis will be carried out from position of $s / L=0$ (evaporator inlet) to $s / L=1$ (evaporator outlet) with an increment of $L / 20$. In each segment, the flow quality, void fraction, phase superficial velocity, and flow pattern will be analyzed. Each analysis will be carried out for evaporating temperature of $-20^{\circ} \mathrm{C}$ to $+5^{\circ} \mathrm{C}$ with an increment of $5^{\circ} \mathrm{C}$. Analysis will be carried out for air conditioning unit with refrigerant R290 using evaporator diameter of $7.9 \mathrm{~mm}$ and $6.3 \mathrm{~mm}$ and cooling capacity of 2.64 and $5.28 \mathrm{~kW}$. R-290 is chosen because it has a low global warming potential, efficient, and suitable for the substitution of R22 and R410A that have been widely used in residential air conditioners (Tritjahjono et al., 2019). It also appropriates for a refrigeration system that use ejector, instead of capillary tube, for its expansion device (Sumeru et al., 2019).

\section{RESULTS AND DISCUSSION}

\subsection{Effects of evaporating temperature on void fraction}

The profile of void fraction for evaporating temperature of $+5^{\circ} \mathrm{C}$ and cooling capacity of $2.64 \mathrm{~kW}$ is presented in Fig. 2. The plot is for pipe diameter of $7.9 \mathrm{~mm}$ or nominal diameter of $3 / 8$ inches, as usually used by old residential air conditioning machines. As can be seen, the minimum void fraction is found at the evaporator inlet, represented by $s / L=0$, and maximum at the evaporator outlet, $s / L=1$. At the inlet of evaporator, the void fraction is 0.932 , meaning that $95.2 \%$ of the area of evaporator is occupied by refrigerant in vapor phase. The remaining $4.48 \%$ of the area is then occupied by liquid. It should be noted that this situation does not describe the mass fraction or flow quality, but volume fraction. Seen from the mass fraction, at the evaporator inlet the fraction of vapor and liquid refrigerant are $24.6 \%$ and $75.4 \%$, respectively. Due to different density of vapor and liquid refrigerant, the volume of pipe occupied by vapor is much higher than that of liquid phase.

As refrigerant travels in the evaporator, the void fraction increases due to the evaporation process along the evaporator. At $s / L=0.1$, the void fraction is 0.953 with the flow quality of 0.322 . At $s / L=0.2$, the void fraction and flow quality are 0.965 and 0.398 , respectively. When $s / L$ reaches 0.9 , the void fraction reaches 0.999 and the flow quality increases to 0.932 . At the evaporator outlet, both parameters have values of 1. Calculation of void fraction for higher cooling capacity $(5.28 \mathrm{~kW})$ results in the similar result. It is because the void fraction mainly depends on the operating condition, instead of cooling capacity.

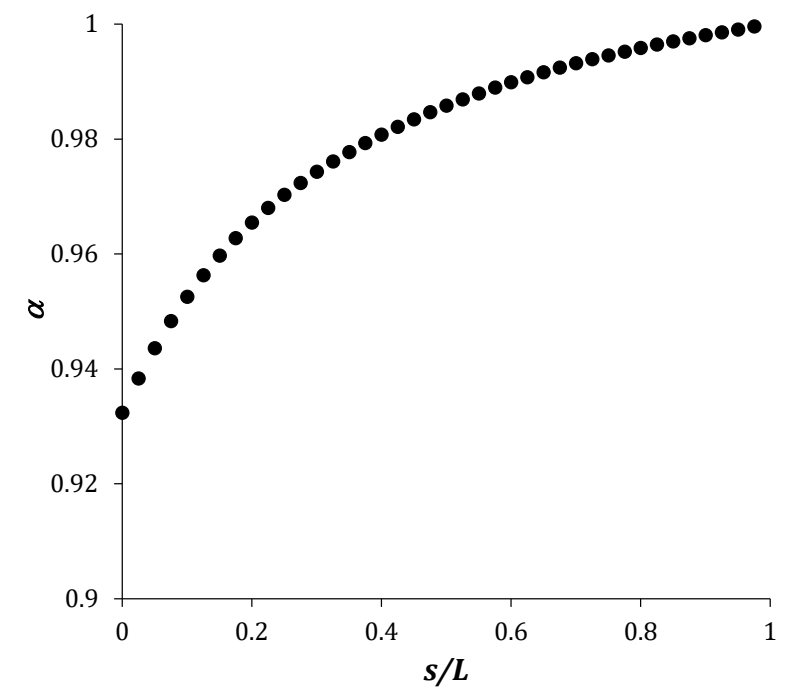

Fig. 2 Void fraction of refrigerant in evaporator for pipe diameter of $7.9 \mathrm{~mm}$ and cooling capacity of $2.64 \mathrm{~kW}$.

At low evaporating temperature, the flow quality $(x)$ will be higher. As an illustration, at evaporating temperature of $+5^{\circ} \mathrm{C}$ the flow quality of refrigerant at the evaporator inlet is 0.246 . At $0^{\circ} \mathrm{C}, x$ increases to 0.281 and reaches 0.384 at evaporating temperature of $-20^{\circ} \mathrm{C}$. This emphasizes the increase of flow quality with the decrease of evaporating temperature. The increase of flow quality causes the increase of void fraction. Fig. 3 depicts the effect of evaporating temperature on the void fraction.

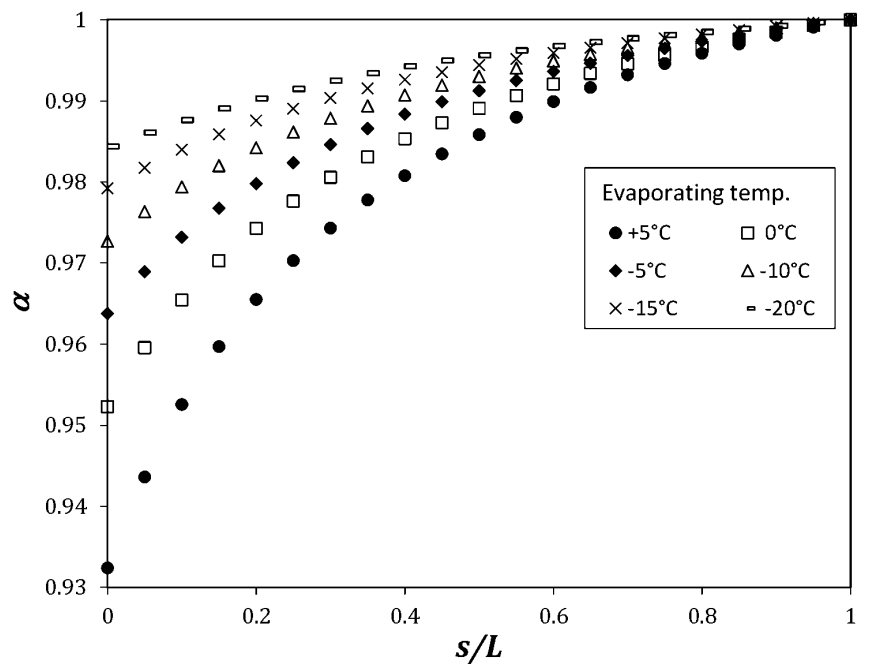

Fig. 3 Effect of evaporating temperature on the void fraction for pipe diameter of $7.9 \mathrm{~mm}$ and cooling capacity of $2.64 \mathrm{~kW}$.

To test the result, the void fraction of the present work is tested by using the correlations from Hammersma and Hart (1987), Cioncolini and Thome (2012), and Setyawan et al. (2019a). The first correlation was developed involving the flow quality and vapor and liquid density. In this correlation, the flow quality has the more significant effect than that of fluid densities. Similar approximation was used by the second correlation. In the third correlation, the void fraction is calculated by employing the ratio of vapor and liquid Reynolds number.

In comparison to the present work, the first correlation gives an average error of about $4.20 \%$, meanwhile the second and third have errors of $3.95 \%$ and $2.67 \%$, respectively. It should be noted that for all 
the three correlations, the larger errors are resulted for low $s / L$ or near evaporator inlet. The errors are then decreased for larger $\mathrm{s} / \mathrm{L}$ and reach its minimum at the evaporator outlet $(s / L=1)$. Fig. 4 describes the comparison of the present work to the three previous correlations. The correlation of Hammersma and Hart (1987) predicts 73\% data within $\pm 5 \%$ error band. Meanwhile, the correlation of Cioncolini and Thome (2012) predicts $77 \%$ and the last correlation from Setyawan et al. (2019a) gives the best performance that can predict all data within $\pm 5 \%$ error band.

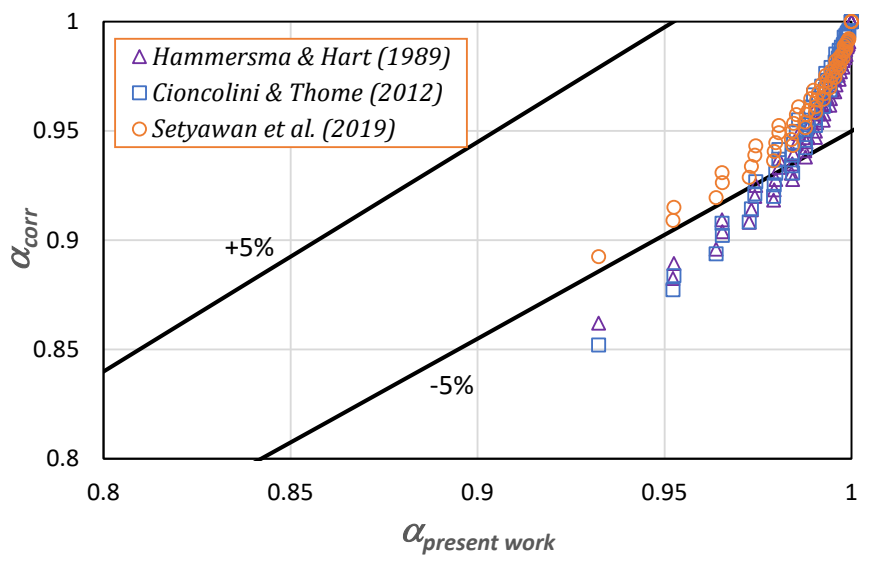

Fig. 4 Comparison of the calculated void fraction with the available previous correlations.

\subsection{Effects of evaporating temperature on flow pattern}

To determine the flow pattern of refrigerant in the evaporator, the superficial velocity of liquid and vapor refrigerant should be calculated first. The resulted superficial liquid and gas velocity $\left(J_{L}\right.$ and $\left.J_{G}\right)$ are then plotted in a flow pattern map (Mandhane et al, 1974). The map has an overall error of $18.2 \%$ in identifying all flow patterns in horizontal pipe. Its individual errors for particular flow pattern are $21.4 \%$ and $28.4 \%$ for wavy and stratified flow, $20.3 \%$ for slug flow, and $7.2 \%$ for annular flow.

The plot of Fig. 5 shows the flow patterns for cooling capacity of $2.64 \mathrm{~kW}$ and evaporator pipe diameter of $7.9 \mathrm{~mm}$ or $3 / 8 \mathrm{in}$. As could be seen, slug, annular and wavy flow could be found when the evaporating temperature is $5^{\circ} \mathrm{C}$. Annular flow is found at $s / L=0.6$ to $s / L=0.7$. As evaporating temperature decreases, the annular pattern vanishes, leaving slug and wavy flow patterns. At evaporating temperature of $0^{\circ} \mathrm{C}, 55 \%$ of slug and $45 \%$ of wavy flow are encountered. Decreasing the evaporator temperature to $-5^{\circ} \mathrm{C},-10^{\circ} \mathrm{C}$, and $-15^{\circ} \mathrm{C}$ resulting in the portion of slug flow of $45 \%, 35 \%$, and $20 \%$, respectively. As the temperature of refrigerant in evaporator decreases, the wavy flow is found at the position closer to the evaporator inlet. At the lowest evaporating temperature, the slug also vanishes, and the remaining regime is wavy. For all 6 different evaporating temperatures from $-20^{\circ} \mathrm{C}$ to $+5^{\circ} \mathrm{C}$, the overall portion of slug flow is $36 \%$, annular flow $3 \%$, and wavy flow $61 \%$. For low evaporating temperature, it is obvious that the dominant pattern is wavy flow.

If the evaporator pipe diameter is changed to $5 / 16$ in $(6.3 \mathrm{~mm})$ with constant cooling capacity, the flow pattern of the refrigerant will also be changed. Under this condition, the wavy flow vanishes and the dominant flow patterns are slug and annular. The decrease of pipe diameter results in the higher superficial velocity of liquid and vapor. The higher $J_{L}$ and $J_{G}$ shift the points in the map in up and right direction and the wavy flow changes to slug and annular.

At evaporating temperature of $+5^{\circ} \mathrm{C}$, slug flow is found in $40 \%$ of pipe segment from $s / L=0$ to $s / L=0.35$. The remaining $60 \%$ of pipe segment is occupied by annular flow. At evaporating temperature of $0^{\circ} \mathrm{C}$ and $-5^{\circ} \mathrm{C}$, the portions of annular flow increase to $65 \%$ and $70 \%$, respectively, and the formation of annular flow is started at $s / L=0.35$ and $s / L=0.3$. Decreasing the evaporating temperature to $-10^{\circ} \mathrm{C}$ and - $15^{\circ} \mathrm{C}$ results in the increase of annular flow portion to $80 \%$ and $85 \%$ and annular flow formation is started at $s / L=0.2$ and $s / L=0.15$, correspondingly. In the lowest evaporating temperature, annular flow is very dominant with an occupancy of $90 \%$. In detail, the annular flow occupies the evaporator pipe from $s / L=0.1$ to $s / L=0.95$. The domination of annular flow in the evaporator is in agreement with visual study of R32 in microchannel reported by Li and Hrnjak (2019).

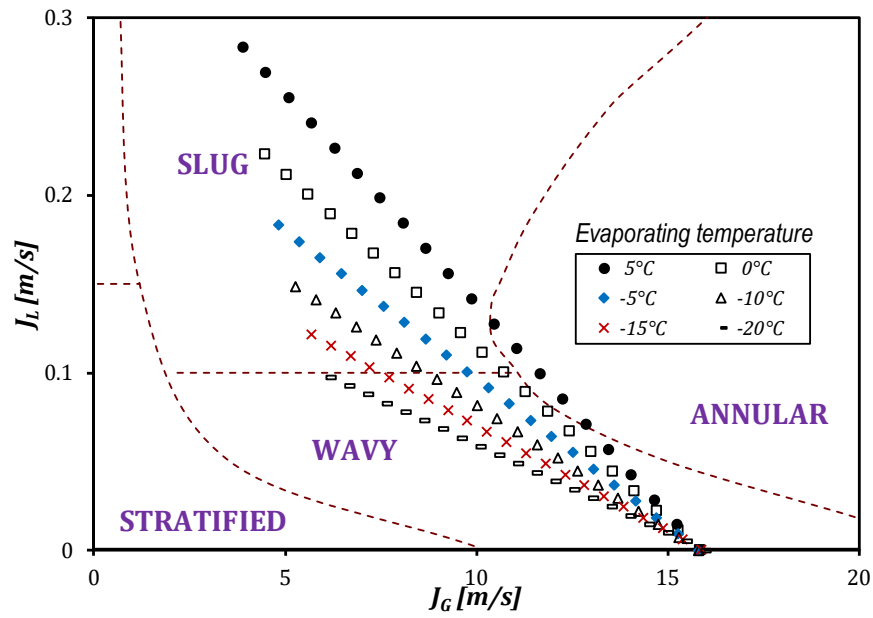

Fig. 5 Effect of evaporating temperature for evaporator pipe diameter $7.9 \mathrm{~mm}$ and cooling capacity $2.64 \mathrm{~kW}$.

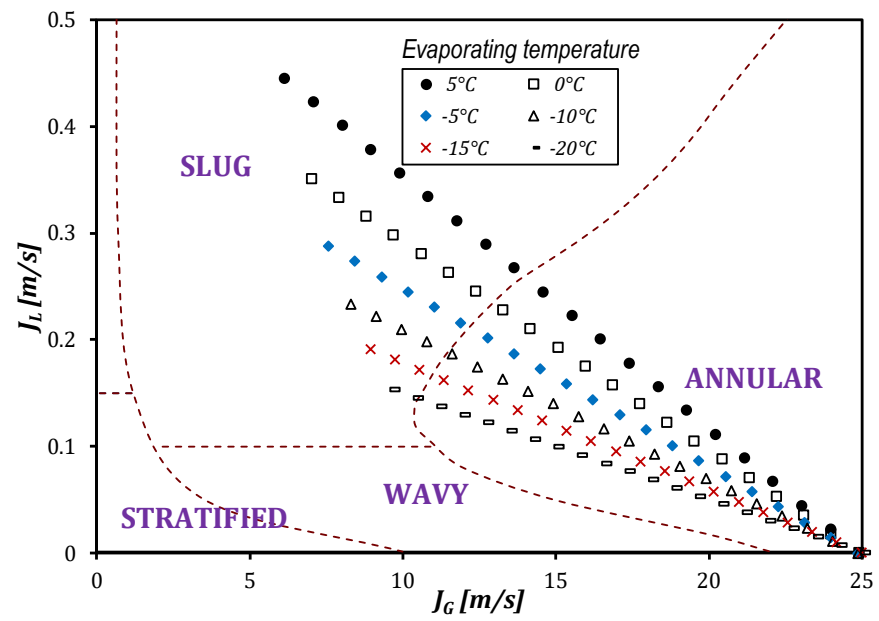

Fig. 6 Effect of evaporating temperature for evaporator pipe diameter $6.3 \mathrm{~mm}$ and cooling capacity $2.64 \mathrm{~kW}$.

The effect of evaporating temperature on the flow pattern for cooling capacity of $2.64 \mathrm{~kW}$ and evaporator diameter of $6.3 \mathrm{~mm}$ is presented in Fig. 6. In total, for all evaporating temperatures studied, the slug occupies $25 \%$ of pipe segment and the remaining $75 \%$ are annular.

To examine the influence of cooling capacity, the flow pattern for evaporator diameter $7.9 \mathrm{~mm}$ and cooling capacity $5.28 \mathrm{~kW}$ is plotted. In comparison to Fig. 5, it is obvious that the superficial velocity of vapor and liquid are doubled. This results in the shifting of wavy flow to slug and annular. In Fig. 5, only 3\% of annular flow exists for all range of evaporating temperature. Doubling the capacity with constant pipe diameter results in the doubled velocity of refrigerant in the evaporator. This affects the flow pattern, as shown in Fig. 7.

For all evaporating temperatures, it apparent that the flow pattern is dominated by annular, similar to condition at cooling capacity of 2.64 $\mathrm{kW}$ and pipe diameter of $6.3 \mathrm{~mm}$. The slug flow occurs at the highest evaporating temperature, occupies the pipe segment form $s / L=0$ to $s / L$ $=0.4$ with portion of $40 \%$. Decreasing the evaporating temperature to 
$0^{\circ} \mathrm{C}$ and $-5^{\circ} \mathrm{C}$ reduces the portion of slug flow to $30 \%$ and $25 \%$, respectively.

At evaporating temperature of $-10^{\circ} \mathrm{C}$ and $-15^{\circ} \mathrm{C}$, the slug flow vanishes at $s / L=0.15$ and $s / L=0.1$, correspondingly. In these conditions, the portion of slug flow decreases $10 \%$ and $5 \%$, respectively. At the lowest evaporating temperature, the slug flow completely vanishes, and all pattern is annular. In general, annular flow dominates when the evaporating temperature is low. For all range of evaporating temperatures, the portion of slug flow is $20 \%$ and annular flow occupies of $80 \%$ of pipe length.

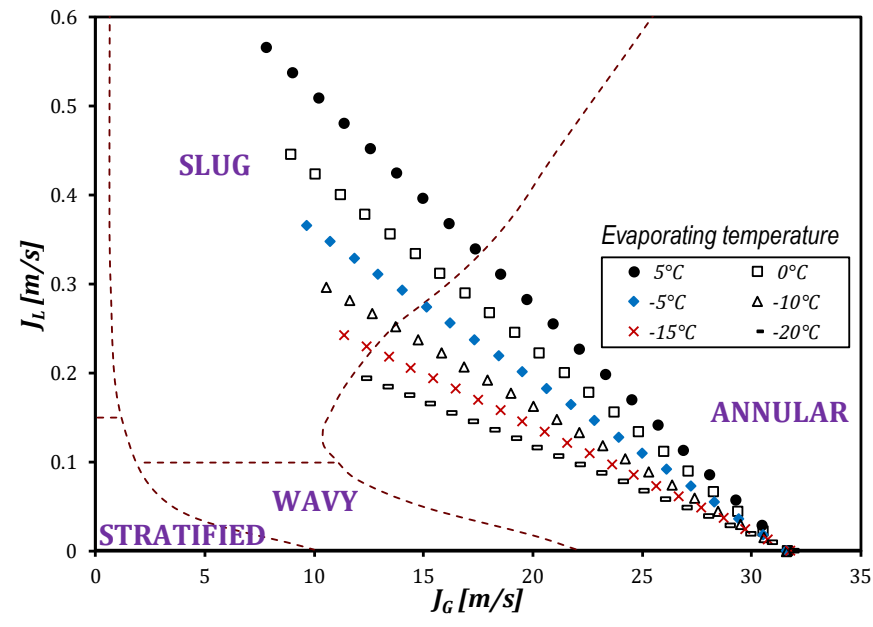

Fig. 7 Effect of evaporating temperature for evaporator pipe diameter $7.9 \mathrm{~mm}$ and cooling capacity $5.28 \mathrm{~kW}$.

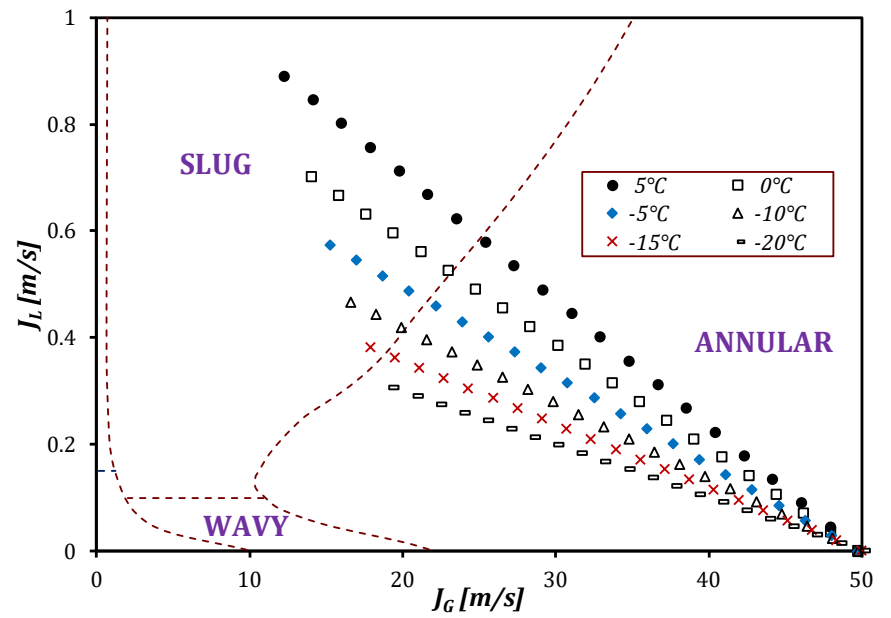

Fig. 8 Effect of evaporating temperature for evaporator pipe diameter $6.3 \mathrm{~mm}$ and cooling capacity $5.28 \mathrm{~kW}$

The profile of flow pattern in the evaporator for cooling capacity of $5.28 \mathrm{~kW}$ and pipe diameter of $6.3 \mathrm{~mm}$ is depicted in Fig. 8. As can be seen, the range of both superficial velocity of vapor and liquid increase due to the decrease of pipe diameter. At evaporating temperature of $5^{\circ} \mathrm{C}$, the slug flow is found at the pipe inlet to $s / L=0.35$, giving the portion of $35 \%$. Starting from $s / L=0.4$ to the outlet of evaporator, the annular flow is formed and occupies $65 \%$ of pipe length. Decreasing the evaporating temperature to $0^{\circ} \mathrm{C}$ and $-5^{\circ} \mathrm{C}$ shift the onset of annular flow to $s / L=0.35$ and $s / L=0.25$, respectively. It means that the annular flow is formed in $60 \%$ and $70 \%$ of pipe length, correspondingly. Further decrease of evaporating temperature to $-10^{\circ} \mathrm{C}$ and $-15^{\circ} \mathrm{C}$ results in the onset of annular flow to $s / L=0.2$ and $s / L=0.1$, implying formation of annular flow in $75 \%$ and $85 \%$ of pipe length, respectively. Again, at evaporating temperature of $-20^{\circ} \mathrm{C}$, annular flow is developed from the inlet to the outlet of evaporator. Totally, the combination of cooling capacity 5.28 $\mathrm{kW}$ and evaporator diameter of $6.3 \mathrm{~mm}$ results in the occupancy of slug flow by $16 \%$ of pipe segment and annular flow by $84 \%$.

\section{CONCLUSION}

The effects of evaporating temperature on the void fraction and flow pattern of refrigerant in a horizontal evaporator with two different diameter and cooling capacity have been analyzed. The testing was conducted under 6 different evaporator temperature, ranges from $-20^{\circ} \mathrm{C}$ to $+5^{\circ} \mathrm{C}$.

The range of void fraction from 0.932 to 0.984 was found at the evaporator inlet. Meanwhile, at the outlet the void fraction is 1 . The higher void fraction is obtained for the lower evaporating temperature. The calculated void fraction has a good agreement with 3 previous correlations and provides an average error of less than $5 \%$.

For all operating conditions, the flow pattern of refrigerant in evaporator was dominated by slug and wavy flow when the study was carried out for the lower cooling capacity $(2.64 \mathrm{~kW})$ and larger pipe size $(7.9 \mathrm{~mm})$. Reducing the pipe diameter to $6.3 \mathrm{~mm}$ results in the vanishing of wavy flow and domination of annular flow by $75 \%$. Doubling the cooling capacity to $5.28 \mathrm{~kW}$ with the smaller evaporator pipe diameter results in increase of domination of annular flow in evaporator.

Generally, higher void fraction and higher portion of annular flow will be resulted for the lower evaporating temperature. It should also be noted that at the lower evaporating temperature, the annular flow will be developed earlier in the pipe segment near the evaporator inlet.

\section{ACKNOWLEDGEMENT}

The author would like to thank to Politeknik Negeri Bandung for the kind support during the planning, implementation, accomplishment of this research.

\section{NOMENCLATURE}

$\begin{array}{ll}A & \text { Area of pipe, } \mathrm{m}^{2} \\ D & \text { Diameter of pipe, } \mathrm{m} \\ J_{G} & \text { Gas superficial velocity, } \mathrm{m} / \mathrm{s} \\ J_{L} & \text { Liquid superficial velocity. } \mathrm{m} / \mathrm{s} \\ L & \text { Length of evaporator, } \mathrm{m} \\ m_{G} & \text { Gas/vapor mass flowrate, } \mathrm{kg} / \mathrm{s} \\ \dot{m}_{L} & \text { Liquid mass flowrate, } \mathrm{kg} / \mathrm{s} \\ Q & \text { Refrigerant volumetric flow rate, } \mathrm{m}^{3} / \mathrm{s} \\ Q_{E} & \text { Evaporator } / \text { cooling capacity, } \mathrm{W} \\ s & \text { Segment length of evaporator, } \mathrm{m} \\ v & \text { Specific volume of refrigerant, } \mathrm{m}^{3} / \mathrm{kg} \\ V & \text { Volume, } \mathrm{m}^{3} \\ x & \text { Vapor quality of refrigerant }\end{array}$

\section{Greek symbols}

$\begin{array}{ll}\alpha & \text { Void fraction } \\ \rho & \text { Density of refrigerant, } \mathrm{kg} / \mathrm{m}^{3}\end{array}$

\section{REFERENCES}

Bhagwat, S. M., and Ghajar, A. J., 2014, "A flow pattern independent drift flux model based void fraction correlation for a wide range of gasliquid two phase flow," International Journal of Multiphase Flow, 59, 186-205.

https://doi.org/10.1016/j.ijmultiphaseflow.2013.11.001

Caniere, H., Bauwens, B., T'Joen, C., De Paepe, M., 2010, "Mapping of horizontal refrigerant two-phase flow patterns based on clustering of capacitive sensor signals," International Journal of Heat and Mass Transfer, 53, 5298-5307. 


\section{https://doi.org/10.1016/j.ijheatmasstransfer.2010.07.027}

Caniere, H., T'Joen, C., Willockx, A., and De Paepe, M., 2008, "Capacitance signal analysis of horizontal two-phase flow in a small tube," Experimental Thermal and Fluid Science, 32, 892-904. https://doi.org/10.1016/j.expthermflusci.2007.10.011

Cioncolini, A., and Thome, J. R., 2012, "Void fraction prediction in annular two-phase flow," International Journal of Multiphase Flow, 43, 72-84.

https://doi.org/10.1016/j.ijmultiphaseflow.2012.03.003

Hamersma, P.J., and Hart, J., 1987, "A pressure drop correlation for gas/liquid pipe flow with a small liquid holdup," Chemical Engineering Science, 42(5), 1187-1196.

https://doi.org/10.1016/0009-2509(87)80068-4

Jassim, E.W., and Newell, T.A., 2006, "Prediction of two-phase pressure drop and void fraction in micro-channels using probabilistic flow regime mapping," International Journal of Heat and Mass Transfer, 49(15-16), 2446-2457.

https://doi.org/10.1016/j.ijheatmasstransfer.2006.01.034

Kanizawa, F.T., and Ribatski, G., 2015, "Void fraction predictive method based on the minimum kinetic energy," Journal of Brazillian Society of Mechanical Science and Engineering, 38(1), 209-225.

https://doi.org/10.1007/s40430-015-0446-x

Li, H., and Hrnjak, P., 2019, "Flow visualization of R32 in parallel-port microchannel tube," International Journal of Heat and Mass Transfer, 128, $1-11$.

https://doi.org/10.1016/j.ijheatmasstransfer.2018.08.120

Mandhane, J. M., Gregory, G. A., and Aziz, K., 1974, “A flow pattern map for gas-liquid flow in horizontal pipes.,". International Journal of Multiphase Flow, 1(4): 537-553.

https://doi.org/10.1016/0301-9322(74)90006-8

Mohseni, S.G., and Akhavan-Behabadi, M.A., 2014, "Flow pattern visualization and heat transfer characteristics of R-134a during evaporation inside a smooth tube with different tube inclinations," International Communications in Heat and Mass Transfer, 59, 39-45. https://doi.org/10.1016/j.icheatmasstransfer.2014.10.018

Ong, C. L., and Thome, J. R., 2009, "Flow boiling heat transfer of R134a, R236fa and R245fa in a horizontal $1.030 \mathrm{~mm}$ circular channel," Experimental Thermal and Fluid Science, 33, 651-663. https://doi.org/10.1016/j.expthermflusci.2009.01.002

Pietrzak, M., and Płaczek, M., 2019, "Void fraction predictive methods in two-phase flow across a small diameter channel," International Journal of Multiphase Flow, 121, 103-115.

https://doi.org/10.1016/j.ijmultiphaseflow.2019.103115

Roman, A.J., Kreitzer, P. J., Ervin, J. S., Hanchak, M. S., and Byrd, L. W., 2015, "Flow pattern identification of horizontal two-phase refrigerant flow using neural networks," International Communications in Heat and Mass Transfer, 71, 254-264.

https://doi.org/10.1016/j.icheatmasstransfer.2015.12.033

Saisorn, S. and Wongwises, S., 2012, "A critical review of recent investigations on flow pattern and heat transfer during flow boiling in micro-channels," Frontiers in Heat and Mass Transfer, 3(1), 1-15. https://doi.org/10.5098/hmt.v3.1.3006

Setyawan, A., Deendarlianto, Indarto, and Neo, F., 2016, "Experimental investigation on liquid film asymmetry in air-water horizontal annular flow," AIP Conference Proceedings, 1737, 040009-1-040009-7. https://doi.org/10.1063/1.4949297
Setyawan, A., Indarto, and Deendarlianto, 2017, "Experimental investigations of the circumferential liquid film distribution of air-water annular two-phase flow in a horizontal pipe," Experimental Thermal and Fluid Science, 85, 95-118.

https://doi.org/10.1016/j.expthermflusci.2017.02.026

Setyawan, A., Indarto, and Deendarlianto, 2019, "Measurement of Liquid Holdup by Using Conductance Probe Sensor in Horizontal Annular Flow," Journal of Advanced Research in Fluid Mechanics and Thermal Sciences, 53(1), 11-24.

Setyawan, A., Indarto, and Deendarlianto, 2019, "Simplified Correlation for Liquid Holdup in a Horizontal Two-Phase Gas-Liquid Annular Flow," Journal of Advanced Research in Fluid Mechanics and Thermal Sciences, 62(1), 20-30.

Shafaee, M., Alimardani, F., and Mohseni, S.G., 2016, “An empirical study on evaporation heat transfer characteristics and flow pattern visualization in tubes with coiled wire inserts," International Communications in Heat and Mass Transfer, 76, 301-307. https://doi.org/10.1016/j.icheatmasstransfer.2016.06.001

Sumeru, K., Pratikto, P., and Setyawan, A., 2019, "The Influence of Room and Ambient Temperatures of Exergy Loss in Air Conditioning Using Ejector as an Expansion Device with R290 as Working Fluid," in E3S Web of Conferences, 2019, 01019, 1-8.

https://doi.org/10.1051/e3sconf/201913001019

Tritjahjono, R.I., Sumeru, K., Setyawan, A., and Sukri, M.F., 2019, "Evaluation of Subcooling with Liquid-Suction Heat Exchanger on the Performance of Air Conditioning System Using R22 / R410A / R290 / R32 as Refrigerants," Journal of Advanced Research in Fluid Mechanics and Thermal Sciences, 55(1), 1-11.

Tu, X., and Hrnjak, P.S., 2004, "Flow and Heat Transfer in Microchannels 30 to 300 Microns in Hydraulic Diameter," Report, Air Conditioning and Refrigeration Center University of Illinois ACRC CR53.

Warsito, W., and Fan, L.S., 2001, "Measurement of real-time flow structures in gas-liquid and gas-liquid-solid flow systems using electrical capacitance tomography (ECT)," Chemical Engineering Science, 56(21-22), 6455-6462.

https://doi.org/10.1016/S0009-2509(01)00234-2

$\mathrm{Xu}, \mathrm{F}$., and Fang, X., 2014, "Correlations of void fraction for two-phase refrigerant flow in pipes," Applied Thermal Engineering, 64, 242-251. https://doi.org/10.1016/j.applthermaleng.2013.12.032

Yang, C-M., and Hrnjak, P., 2020, “A new flow pattern map for flow boiling of R410A in horizontal micro-fin tubes considering the effect of the helix angle," International Journal of Refrigeration, 109, 154-160. https://doi.org/10.1016/j.ijrefrig.2019.09.013

Yashar, D. A., Wilson, M. J., Kopke, H. R., Graham, D. M., Chato, J. C., and Newell, T. A., 2001, "An Investigation of Refrigerant Void Fraction in Horizontal, Microfin Tubes," HVAC\&R Research, 7(1), 67-82. https://doi.org/10.1080/10789669.2001.10391430

Zhuang, X., Gong, M., Chen, G., Zou, X., and Shen, J., 2016, "Twophase flow pattern map for R170 in a horizontal smooth tube," International Journal of Heat and Mass Transfer, 102, 1141-1149. https://doi.org/10.1016/j.ijheatmasstransfer.2016.06.094

Zürcher, O., Favrat, D., and Thome, J.R., 2002, "Evaporation of refrigerants in a horizontal tube: an improved flow pattern dependent heat transfer model compared to ammonia data," International Journal of Heat and Mass Transfer, 45, 303-317. https://doi.org/10.1016/S0017-9310(01)00145-4 